\title{
Gastric Body Carcinoma
}

National Cancer Institute

\section{Source}

National Cancer Institute. Gastric Body Carcinoma. NCI Thesaurus. Code C8399.

A carcinoma that arises from the body of the stomach. 